\title{
Hepatic EROD activity in dab Limanda limanda in the German Bight using an improved plate-reader method
}

\author{
Martin Eggens ${ }^{1}$, François Galgani ${ }^{2}$, Jarle Klungsøyr ${ }^{3}$, James Everts ${ }^{1}$ \\ ${ }^{1}$ Ministry of Transport and Public Works, Tidal Waters Division, Ecotoxicology Section, PO Box 207, 9750 AE Haren, \\ The Netherlands \\ ${ }^{2}$ IFREMER, Centre de Nantes, PO Box 1049, F-44037 Nantes Cédex 01, France \\ ${ }^{3}$ Institute of Marine Research, Dept of Chemical Oceanography, PO Box 1870, N-5024 Bergen, Norway
}

\begin{abstract}
During the Bremerhaven Workshop an improved, fast and easy method for the determination of ethoxyresorufin-O-deethylase (EROD) activity in dab Limanda limanda liver was tested. The improvement involved the use of a $12500 \times \mathrm{g}$ supernatant instead of the microsomal fraction, thus omitting the need for long ultra-centrifugations which cannot be carried out aboard a research vessel. EROD activities in the $12500 \times g$ supernatant and in the microsomal suspension were well correlated. Despite its disadvantages of lower specific EROD activity, higher minimum detection limit and higher analytical variance, the $12500 \times \mathrm{g}$ supernatant was used for further analysis. EROD activity in dab liver showed a spatial trend corresponding to a pollution gradient in the German Bight. EROD activity was highest at sampling sites near to the Elbe and Weser estuaries. The same trend was found in liver concentrations of PCB and lindane, but not of heavy metals and other pesticides
\end{abstract}

\section{INTRODUCTION}

The framework of this study is an investigation into the relative sensitivity and practical applicability of various field measurements of exposure of the marine ecosystem to contaminants. An international multidisciplinary field survey was carried out in the German Bight; this included measurement of biochemical stress responses, histopathology in fish and analysis of contaminants in fish liver and in sediments. In this paper we present the results of measurements of one of these variables: ethoxyresorufin-O-deethylase (EROD) activity in the dab Limanda limanda.

The mono-oxygenase system (MO) plays an important role in the biotransformation of organic xenobiotic substances and is the first step in the eventual degradation and excretion of these compounds. Ethoxyresorufin is a model substrate used to measure the induction of one of the isozymes of the MO-system: cytochrome P4501A1. This isozyme can be induced specifically by planar molecules, such as some poly- chlorinated biphenyls (PCBs) and polycyclic aromatic hydrocarbons (PAHs) (Nebert \& Gonzalez 1987).

Measurements of EROD activity have been widely used in environmental monitoring programmes and other field studies to indicate exposure of organisms to these compounds (Addison \& Edwards 1988, Stegeman et al. 1988, Sulaiman et al. 1991). During the Oslo Workshop, held in 1986, EROD activity in flounder Platichthys flesus appeared to show the clearest and most sensitive biochemical response to expected pollutant gradients in the field (Addison 1988). To apply the method of EROD activity measurement in marine monitoring programmes, a technique was developed by Eggens \& Galgani (1992) which increases its speed. This new development was crucial for the present study since it was the basis of a method which facilitates measurements aboard a vessel.

The survey was carried out using dab, which was chosen because the species is widely distributed in the study area, and as a bottom dweller it is exposed directly to contaminants in the sediment. 


\section{MATERIALS AND METHODS}

Chemicals. The chemicals used were glycerin from Sigma Chemical Company, ethoxyresorufin and NADPH from Boehringer Mannheim b.v., resorufin from Aldrich Chemie and potassium chloride $(\mathrm{KCl})$, EDTA (Titriplex III), sodium di-hydrogen phosphate and potassium mono-hydrogen phosphate from Merck Nederland b.v.

Fish collection. Female dab (length $>25 \mathrm{~cm}$ ) were collected by beam trawling at Stns $3,5,6,7,8 \& 9$ in the German Bight and at Stns A \& R at a former drilling site (Fig. 1).

Preparation of $12500 \mathrm{~g}$ supernatant and microsomal fraction. After dissection, the livers were rinsed with ice-cold $1.15 \% \mathrm{KCl}$ solution and stored in liquid nitrogen $\left(-196^{\circ} \mathrm{C}\right)$. Within $1 \mathrm{wk}$ they were homogenized in a Potter-tube after adding 3 times the volume $1.15 \% \mathrm{KCl}$ solution containing $20 \%$ glycerin. The solution was buffered with $0.1 \mathrm{M}$ phosphate $(\mathrm{pH} 7.4)$ The homogenate was centrifuged for $20 \mathrm{~min}$ at 12500 $\times g$ in a Microcentaur $\left.{ }^{(}\right)$which was stored in a refrigerator $\left(4^{\circ} \mathrm{C}\right)$ before use. After centrifugation, $25 \mu \mathrm{l}$ supernatant was used to measure the EROD activity. The supernatants from 20 samples from the Drilling Site stations were centrifuged at $100000 \times g$ for $1 \mathrm{~h}$ in a refrigerated ultracentrifuge $\left(4^{\circ} \mathrm{C}\right)$. The pellets containing the microsomes were resuspended in $1.5 \mathrm{ml}$ phosphate buffer (0.1 M; pH 7.4) containing $20 \%$ glycerin, and used for EROD measurements. All operations were carried out in ice as much as possible.

Protein analysis. The analysis of the protein content was carried out by the method of Bradford (1976) on a Titertek UV NIS plate-reader (model Multiskan MCC 340 MK II).

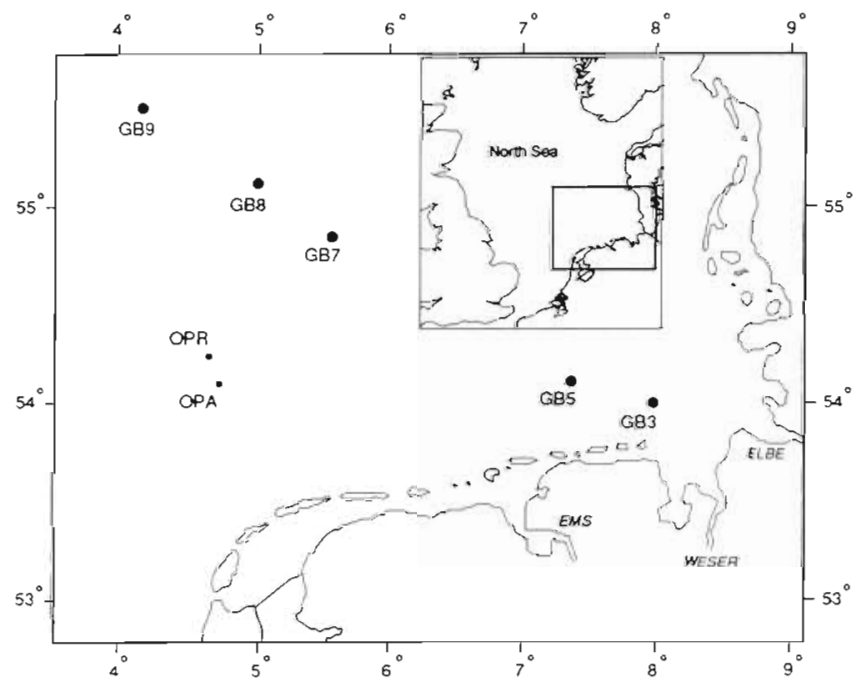

Fig. 1. The North Sea showing German Bight sampling Stns 3 to 9 (GB3 to GB9) and drilling sites A \& R (OPA and OPR)
EROD measurement. For the EROD activity measurement the plate-reader method described by Eggens \& Galgani (1992) was used with an external resorufin standard to which $25 \mu \mathrm{l}$ of either the microsomal suspension or the $12500 \times g$ supernatant was added. The values for the EROD activity are shown as units (U) $\mathrm{mg}^{-1}$ protein ( $1 \mathrm{U}=1 \mathrm{pmol}$ resorufin formed per min).

Statistics. Means and $95 \%$ confidence limits of the data at each sampling site were calculated after logtransformation and retransformation. To test differences in EROD activity between the stations, a TukeyKramer test was carried out; this is an ANOVA which allows for differences in population size. The EROD activity data were compared, by correlation, with the concentrations of $\mathrm{PCB}$, pesticide and heavy metal concentrations in dab liver from the same stations. Both ANOVA and calculation of correlations were carried out with the SYSTAT computer programme (release 5.0; SYSTAT Inc.).

The minimum detection limit (MDL) of the assay was calculated as twice the standard deviation of the standard blanks using either $12500 \times g$ supernatants or microsomal suspensions.

Analysis of PCBs, pesticides and heavy metals. The analyses were carried out as described by Cofino et al. (1992).

\section{RESULTS AND DISCUSSION}

\section{Methodology}

The correlation between the results of the 2 methods for sample preparation was high (Fig. $2, \mathrm{r}^{2}=0.97, \mathrm{p}<$ $0.001)$. However, EROD activity normalised to protein content in the $12500 \times g$ supernatant ('supernatant', below) was about 4 times lower than when measured in the microsomal suspension ('microsomes', below). This could be due to the amount of non-specific proteins which would be removed during the $100000 \times g$ centrifugation in the isolation of the microsomes. Also, the action of DT-diaphorase cannot be ignored (Nims et al. 1984). This enzyme, which can oxidise resorufin and is present in the cytosol, could also contribute to lower apparent EROD activities in the supernatant.

The standard deviations of the standard blank using supernatant and microsomes were 5.5 and 15 respectively, and the calculated MDLs were 9.4 and $25.8 \mathrm{U}$ $\mathrm{ml}^{-1}$ sample. For a sample with $3 \mathrm{mg} \mathrm{ml}^{-1}$ protein, which is the maximum concentration for a reliable EROD measurement using the plate-reader method (Eggens \& Galgani 1992), the MDLs expressed as U $\mathrm{mg}^{-1}$ protein will be approximately 3 for microsomal samples and 8 for supernatants. Since the amount of protein added to the reaction vial is limited, and the su- 


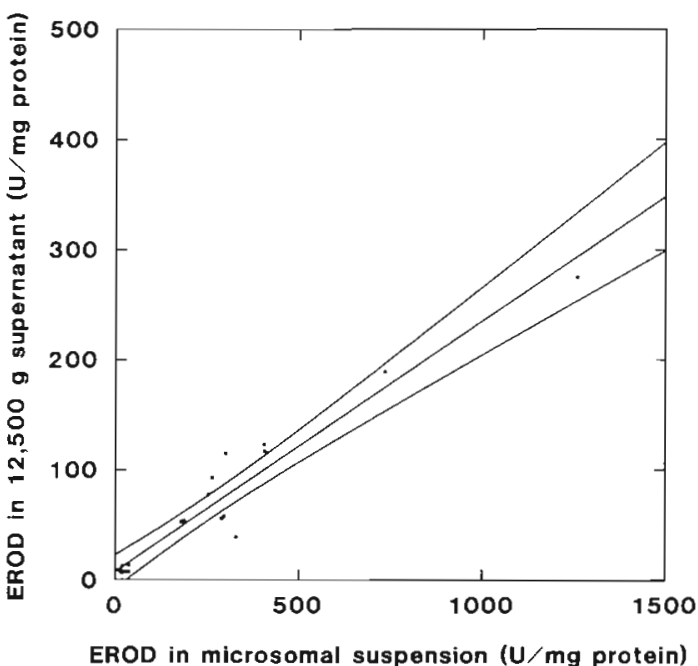

Fig. 2. Correlation between EROD activity measured in the supernatant and that measured in the microsomes $\left(\mathrm{r}^{2}=0.97\right.$, $\mathrm{p}<0.001$ ). EROD activities are given in $\mathrm{U} \mathrm{mg}^{-1}$ protein ( $1 \mathrm{U}$ $=1 \mathrm{pmol}$ resorufin formed $\mathrm{min}^{-1}$ )

pernatant contains more protein relative to the EROD activity, MDLs are higher than with microsomes. In samples with very low EROD activity and high protein content, the MDL may be too high. However, in this work, hepatic EROD activities measured in dab liver were high enough to be detected in supernatant

The variance in sample measurements was also calculated for both microsomes and supernatant. The mean relative standard deviations were 4.4 and $8.4 \%$ of the mean, respectively ( $n=20$ samples measured in quadruplicate). This implies that the variance in sample measurement is larger in supernatant than in

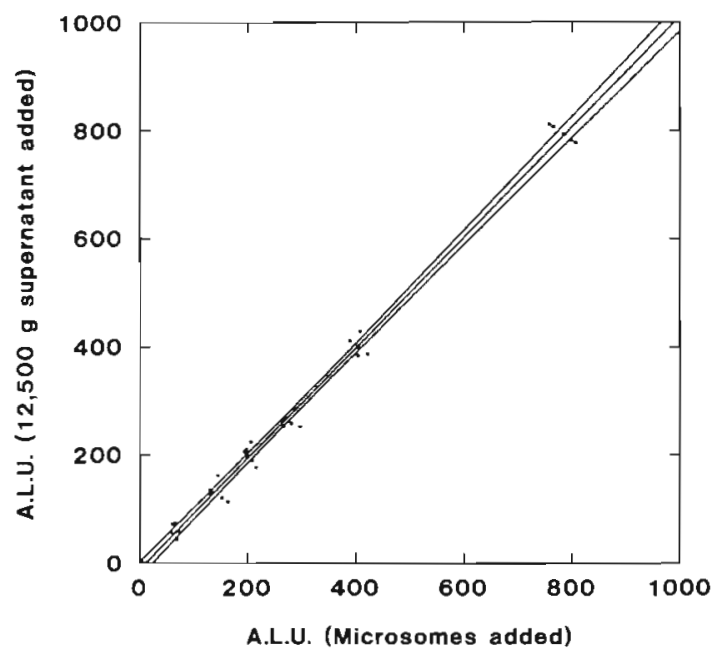

Fig. 3. Correlation (with $95 \%$ confidence limits) between the resorufin standard curve to which microsomes were added and the curve with added supernatant, showing the absence of any difference in quenching by the 2 preparations. The values are expressed as arbitrary luminescence units (A.L.U.) microsomes. However, this analytical variance is small when compared to the biological variance in field measurements, where the variance is often $100 \%$ (cf. Addison \& Edwards 1988, Stegeman et al. 1988)

To examine the possible quenching of the fluorescence, the external standard was measured with both supernatant and microsomes. In Fig. 3 the relation between the 2 standard curves is shown. The slope of the regression did not differ significantly from 1.00, nor the intercept from zero. Therefore, it can be concluded that there is no difference in the quenching of the fluorescence by the enzyme preparations

The main advantages of using supernatant instead of microsomes are the following.

(1) The preparation of microsomes requires an ultracentrifuge, which cannot be operated aboard a ship.

(2) The ultracentrifuge can be omitted when the supernatant is used, which saves time (1 h of centrifugation and $0.5 \mathrm{~h}$ start-up and slow-down per 10 or 12 samples) and money.

(3) Using the supernatant directly aboard a ship avoids the loss of enzyme activity during storage of samples before processing in a well-equipped laboratory (Förlin \& Andersson 1985, Monod \& Vindimian 1991).

Although these results are promising, the method should be developed further. The causes of higher MDLs and relative standard deviations when supernatants are used, and the possible effects of DTdiaphorase should be studied. It should also be determined whether the specific EROD activity in supernatant bears a constant relationship to that in the microsomes at all locations.

\section{EROD activity and the pollution gradient}

The results of our measurements are presented in combination with the chemical analytical data from Cofino et al. (1992) (Table 1).

EROD activity showed a high variation at all sampling sites (Fig. 4). The variation at German Bight Stns $3 \& 7$ are highest due to one extreme value at each site. At Stn 6 only one observation was made. It will be excluded from further discussion.

In the German Bight transect (Stns 3 to 9) the following trend can be seen (Fig. 4): at Stns 3 \& 5 EROD activities tended to be higher than at Stns 7, 8, \& 9 . Furthermore, in the latter group, samples from $\operatorname{Stn} 8$ showed a tendency to higher EROD levels than those from Stns 7 \& 9. EROD activity at Stn 3 differed significantly from that measured at Stns $7 \& 9$ ( $p<0.05)$. EROD activity measured at the former drilling site is shown in the same figure. At Stns A \& R the EROD activities were in the same range as those from 
Table 1. EROD activities and chemical analyses (from Cofino et al. 1993) in dab Limanda limanda liver from the German Bight transect (Stns 3 to 9) and from the drilling sites A \& R. Data are shown as means (SD)

\begin{tabular}{|c|c|c|c|c|c|c|c|}
\hline & 3 & 5 & 7 & $\begin{array}{c}\text { Station } \\
8\end{array}$ & 9 & A & $\mathrm{R}$ \\
\hline$E^{2} O D^{*}$ & 156 & 74 & 19 & 35 & 20 & 36 & 23 \\
\hline $\log (E R O D)$ & $2.2(0.8)$ & $1.9(0.5)$ & $1.3(0.6)$ & $1.5(0.6)$ & $1.3(0.5)$ & $1.6(0.3)$ & $1.4(0.4)$ \\
\hline \multicolumn{8}{|c|}{ Heavy metals } \\
\hline$A S^{b}$ & $13(12)$ & $13(10)$ & $48(19)$ & $42(14)$ & $28(8)$ & $48(12)$ & $55(0)$ \\
\hline $\mathrm{Cd}^{\mathrm{c}}$ & $<50$ & $95(53)$ & $123(50)$ & $167(12)$ & $162(51)$ & $75(7)$ & $<50$ \\
\hline $\mathrm{Cu}^{\mathrm{b}}$ & $4.1(1.7)$ & $5.4(1.9)$ & $7.0(1.3)$ & $5.1(0.7)$ & $2.6(0.6)$ & $6.6(1.5)$ & $6.4(0.2)$ \\
\hline $\mathrm{Hg}^{\mathrm{C}}$ & $86(17)$ & $103(10)$ & $83(12)$ & $100(10)$ & $58(18)$ & $105(35)$ & $70(14)$ \\
\hline $\mathrm{Zn}^{\mathrm{b}}$ & $25.2(3.4)$ & $24.7(1.8)$ & $27.5(2.7)$ & $26.1(0.5)$ & $22.9(4.3)$ & $26.2(0.8)$ & $24.9(2.1)$ \\
\hline \multicolumn{8}{|l|}{ Pesticides $^{\mathrm{d}}$} \\
\hline $\mathrm{A}-\mathrm{HCH}$ & $11.4(2.3)$ & $9.5(2.1)$ & $19.0(1.0)$ & $19.7(1.2)$ & $12.3(2.0)$ & $14.0(1.4)$ & $14.5(5.0)$ \\
\hline $\mathrm{HCB}$ & $34.8(4.9)$ & $43.3(8.6)$ & $29.3(4.0)$ & $31.7(1.2)$ & $35.0(4.3)$ & $31.5(9.2)$ & $28.0(4.2)$ \\
\hline $\mathrm{B}-\mathrm{HCH}$ & $5.0(1.0)$ & $4.5(1.0)$ & $4.5(1.8)$ & $3.1(0.1)$ & $0.4(2.4)$ & $5.0(3.3)$ & $6.6(2.9)$ \\
\hline Lindane & $51(13)$ & $34.8(8.5)$ & $30.7(4.0)$ & $25.0(0.7)$ & $8.6(1.2)$ & $26.0(4.2)$ & $28.0(7.1)$ \\
\hline Aldrin & $3.2(1.3)$ & $3.8(1.1)$ & $9.8(4.4)$ & $8.8(1.9)$ & $4.6(1.9)$ & $5.2(2.0)$ & $6.8(4.5)$ \\
\hline $0, p^{\prime}-\mathrm{DDE}$ & $55(98)$ & $10.9(1.4)$ & $18.7(8.6)$ & $60(61)$ & $14.5(8.3)$ & $12.1(4.2)$ & $12.5(3.5)$ \\
\hline Dieldrin & $60(12)$ & $52(12)$ & $52.0(5.6)$ & $56.0(1.7)$ & $53(11)$ & $50.5(6.4)$ & $50.0(4.2)$ \\
\hline$p, p^{\prime}-\mathrm{DDE}$ & $155(31)$ & $186(134)$ & $148(31)$ & $184(32)$ & $185(65)$ & $142(17)$ & $112(29)$ \\
\hline$o, p^{\prime}-\mathrm{DDD}$ & $4.2(0.9)$ & $4.7(0.5)$ & $4.1(-)$ & $3.8(-)$ & $3.8(0.4)$ & & \\
\hline$p, p^{\prime}-\mathrm{DDD}$ & $41(11)$ & $44(20)$ & $20.7(4.0)$ & $26.3(0.6)$ & $30(12)$ & $24(11)$ & $14.5(5.0)$ \\
\hline$p, p^{\prime}-\mathrm{DDT}$ & $4.5(1.2)$ & $6.3(2.9)$ & $1.8(0.2)$ & $3.9(-)$ & $10.0(7.1)$ & $2.7(-)$ & $3.1(0.1)$ \\
\hline \multicolumn{8}{|c|}{ Polychlorinated biphenyls ${ }^{d}$} \\
\hline CB-28 & $13.3(6.9)$ & $9.3(3.0)$ & $5.4(1.0)$ & $6.5(0.3)$ & $6.4(0.3)$ & $6.7(2.1)$ & $5.9(1.7)$ \\
\hline CB-31 & $7.2(3.0)$ & $4.8(0.9)$ & $2.6(0.5)$ & $3.8(1.1)$ & $3.3(0.3)$ & $2.9(0.6)$ & $2.7(0.6)$ \\
\hline CB-52 & $32(14)$ & $24(12)$ & $16.0(8.7)$ & $28(13)$ & $27(17)$ & $23.5(9.2)$ & $14.5(5.0)$ \\
\hline CB-101 & $128(54)$ & $92(40)$ & $40(17)$ & $59(23)$ & $49(14)$ & $53(11)$ & $32.5(9.2)$ \\
\hline CB-105 & $57(30)$ & $35.3(8.7)$ & $13(17)$ & $13.2(5.5)$ & $19.4(4.0)$ & $17.5(3.5)$ & $11.0(4.3)$ \\
\hline $\mathrm{CB}-118$ & $164(78)$ & $117(42)$ & $49(14)$ & $75(27)$ & $58(10)$ & $67(12)$ & $42(21)$ \\
\hline$C B-128$ & 45 (19) & $25(10)$ & $10.7(3.0)$ & $14.4(6.0)$ & $12.3(4.1)$ & $15.0(0.0)$ & $11.4(3.7)$ \\
\hline CB-138 & $400(10)$ & $275(129)$ & $108(23)$ & $128(33)$ & $119(52)$ & $148(44)$ & $93(27)$ \\
\hline CB-149 & $138(57)$ & $66(25)$ & $23.0(8.2)$ & $31(12)$ & $22.2(4.0)$ & $29.5(9.2)$ & $19.0(2.8)$ \\
\hline CB-153 & $496(125)$ & $327(158)$ & $135(17)$ & 159 (39) & $157(98)$ & $196(44)$ & $121(35)$ \\
\hline CB-156 & $23(12)$ & $15.0(8.9)$ & $6.7(2.0)$ & $7.0(1.9)$ & $6.0(3.2)$ & $7.4(3.0)$ & $4.8(2.3)$ \\
\hline CB- 170 & $40(17)$ & $23.3(9.0)$ & $9.3(1.5)$ & $12.2(3.3)$ & $8.2(5.0)$ & $14.5(0.7)$ & $9.7(1.8)$ \\
\hline CB-180 & $102(41)$ & $61(29)$ & $34.7(7.2)$ & $38.1(8.2)$ & $30(20)$ & $49.5(2.1)$ & $34.0(7.1)$ \\
\hline \multicolumn{8}{|c|}{$\begin{array}{l}\text { Mean EROD activity is calculated after log-transformation and given in pmol } \min ^{-1} \mathrm{mg}^{-1} \text { protein } \\
{ }^{\mathrm{b}} \text { Values are given as } \mu \mathrm{g} \mathrm{g}^{-1} \text { wet wt } \\
\text { c Values are given as } \mathrm{ng} \mathrm{g}^{-1} \text { wet wt } \\
{ }^{\mathrm{d}} \text { Values of all the pesticides and PCBs are given as } \mathrm{ng} \mathrm{g}^{-1} \text { total fat }\end{array}$} \\
\hline
\end{tabular}

German Bight Stns 8 \& 9. There were no significant differences between EROD activities at any other sites.

EROD activity was very highly correlated with the concentrations of all the individual PCB congeners in the liver (Table 2) except for IUPAC \# 52. No correlation was found with pesticides or heavy metals, except for the pesticide lindane. This observation was in agreement with the results of Addison \& Edwards' (1988) study on flounder. These authors found a correlation between EROD activity and total PCB concentrations, both measured in livers. However, it should be kept in mind that no multiple correlations have been calculated on results of the presented study. As a consequence, the correlations reflect strong trends, rather than demonstrating causal relationships with single compounds.

\section{CONCLUSIONS}

(1) Although some additional research should be done, the use of supernatants, together with the platereader method is a promising approach to measuring EROD activity in fish tissues during cruises.

(2) The use of supernatants instead of microsomes for EROD measurements resulted in a 2.7 -fold increase of minimum detection limit and a 2 -fold increase of relative standard deviation per sample. 


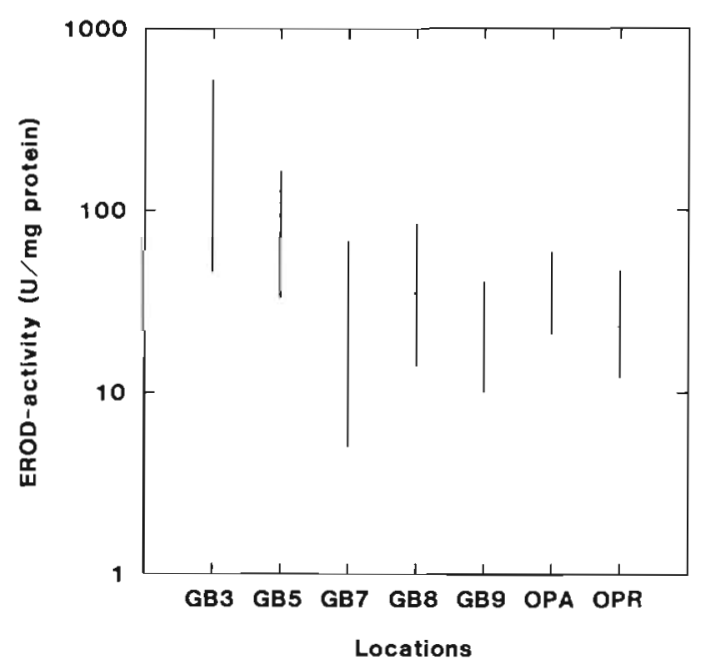

Fig. 4. Mean EROD activity (with $95 \%$ confidence limits) for Stns $3,5,7,8 \& 9$ (GB3, GB5, GB7, GB8 \& GB9) and from the drilling sites $A \& R$ (OPA and OPR). Note the logarithmic scale on the $y$-axis, as EROD activities were calculated after log-transformation

(3) A trend in EROD activity in dab Limanda limanda liver was found in an expected pollution gradient in the German Bight.

(4) EROD activity in dab in the area studied was correlated with PCB burden for all congeners analyzed in dab liver, except IUPAC \# 52.

(5) Among the pesticides analyzed, only lindane, and none of the heavy metals, were correlated with EROD activity.

Acknowledgements. We are very grateful to Dr Ian Davies for providing the heavy metal analysis in dab liver. We also thank Rob Jungcurt for making the drawings.

\section{LITERATURE CITED}

Addison, R. F. (1988). Biochemical effects of a pollutant gradient-summary. Mar. Ecol. Prog. Ser. 46: 75-77

Addison, R. F., Edwards, A. J. (1988). Hepatic microsomal mono-oxygenase activity in flounder Platichthys flesus from polluted sites in Langesundfjord and from mesocosms experimentally dosed with diesel oil and copper. Mar. Ecol. Prog. Ser. 46: 51-54

Bradford, M. M. (1976). A rapid and sensitive method for the quantitation of microgram quantities of protein utilizing the principle of protein-dye binding. Anal. Biochem. 72 : $248-254$

Cofino, W. P., Smedes, F., de Jong, S. A., Abarnou, A., Boon J. P., Oostingh, I., Davies, I. M., Klungsøyr, J., Wilhelmsen, S., Law, R. J., Whinnett, J A., Schmidt, D., Wilson, S. (1992). The chemistry programme. Mar. Ecol. Prog. Ser. 91: $47-56$

Eggens, M. L., Galgani, F. (1992). Ethoxyresorufin-O-deethylase (EROD) activity in flatfish: fast determination with a fluorescence plate-reader. Mar. environ. Res. 33: 213-221

Förlin, L., Andersson, T. (1985). Storage conditions of rainbow
Table 2. Correlation coefficients of several contaminants measured in livers of dab Limanda limanda from the German Bight and Drilling Site gradients, as described in text, with hepatic EROD activity

\begin{tabular}{|c|c|c|}
\hline Contaminant & r & Significance $^{\mathrm{d}}$ \\
\hline \multicolumn{3}{|l|}{ Heavy metals } \\
\hline Arsenic & 0.561 & \\
\hline Cadmium & 0.241 & \\
\hline Copper & 0.093 & \\
\hline Mercury & 0.060 & \\
\hline Zinc & 0.007 & \\
\hline \multicolumn{3}{|l|}{ Pesticides } \\
\hline$\alpha-\mathrm{HCH}$ & 0.272 & \\
\hline $\mathrm{HCB}$ & 0.046 & \\
\hline$\beta-\mathrm{HCH}$ & 0.033 & \\
\hline Lindane & 0.630 & \\
\hline Aldrin & 0.405 & \\
\hline$o, p^{\prime}-\mathrm{DDE}$ & 0.278 & \\
\hline Dieldrin & 0.012 & \\
\hline$p, p^{\prime}-\mathrm{DDE}$ & 0.012 & \\
\hline $0, p^{\prime}-\mathrm{DDD}$ & 0.192 & \\
\hline$p, p^{\prime}-\mathrm{DDD}$ & 0.580 & \\
\hline$p, p^{\prime}-\mathrm{DDT}$ & 0.002 & \\
\hline \multicolumn{3}{|c|}{ Polychlorinated biphenyls } \\
\hline CB-28 & 0.991 & $\cdots$ \\
\hline CB-31 & 0.971 & $\cdots$ \\
\hline $\mathrm{CB}-52$ & 0.550 & \\
\hline CB-101 & 0.961 & $\cdots$ \\
\hline CB-105 & 0.975 & $\cdots$ \\
\hline CB-118 & 0.966 & $\cdots$ \\
\hline CB- 128 & 0.998 & $\cdots$ \\
\hline CB- 138 & 0.939 & $\cdots$ \\
\hline $\mathrm{CB}-149$ & 0.997 & $\cdots$ \\
\hline CB-153 & 0.981 & $\cdots$ \\
\hline CB-156 & 0.977 & $\cdots$ \\
\hline $\mathrm{CB}-170$ & 0.995 & $\cdots$ \\
\hline CB- 180 & 0.986 & $\cdots$ \\
\hline \multicolumn{3}{|c|}{${ }^{a}$ Significance: ${ }^{\cdot}=p<0.05 ; \cdots=p<0.01 ; \cdots=p<0.001$} \\
\hline
\end{tabular}

trout liver cytochrome P-450 and conjugating enzymes. Comp. Biochem. Physiol. 80B: 569-572

Monod, G., Vindimian, E. (1991). Effect of storage conditions and subcellular fractionation of fish liver on cytochrome P450-dependent enzymatic activities used for the monitoring of water pollution. Water Res. 25: 173-177

Nebert, D. W., Gonzalez, F. J. (1987). P-450 genes: structure, evolution, and regulation. Ann. Rev. Biochem. 56: 945-993

Nims, R. W., Prough, R. A., Lbet, R. A. (1984). Cytosol-mediated reduction of resorufin: a method for measuring quinone oxido-reductase. Arch. Biochem. Biophys. 229: $459-465$

Stegeman, J. J., Woodin, B. R., Goksøyr, A. (1988). Apparent cytochrome P-450 induction as an indication of exposure to environmental chemicals in the flounder Platichthys flesus. Mar. Ecol. Prog. Ser. 46: 55-60

Sulaiman, N., George, S., Burke, M. D. (1991). Assessment of sublethal pollutant impact on flounders in an industrialised estuary using hepatic biochemical indices. Mar. Ecol. Prog. Ser. 68: 207-212 